\title{
ANNOUNCEMENTS
}

\section{JADD Announcements for October 2009}

\section{Call for Cases}

Childhood Disintegrative Disorder

In an effort to understand more about childhood disintegrative disorder (CDD) and the phenomenon of regression in autism spectrum disorders, we are collecting clinical case information from practitioners in the community. Cases eligible for this project include those where a diagnosis of CDD was given, or those in which multiple symptoms of CDD were present. Data will be used by members of the DSM V Workgroup on Developmental Disabilities in re-evaluating diagnostic criteria for CDD in DSM V.

For use in this important project, it is required that case histories are very detailed. Cases submitted must be completely de-identified. Histories should include the following elements, if possible:

- Early developmental history.

- Detailed description of period of regression (including age at occurrence, duration of deterioration and skills lost).
- Any available formal ASD diagnostic testing (ADOS, ADI-R, CARS, etc.).

- Any available cognitive testing (DQ, IQ scores or surrogate measures).

- Description of any co-morbid medical conditions and results of medical work-up (e.g. EEG, MRI, genetics, psychiatric).

- Outcome data (recovery of skills, plateau, or further deterioration).

- Treatment history for child (e.g. medications, behavioral treatment).

If you have cases in your practice please consider joining this important effort. The Office of Human Subjects Research at the National Institutes of Health has approved sharing of clinical data for this project (PI DSM V Workgroup Chair, Susan Swedo) as long as the subjects are completely de-identified.

If you have further questions, or would like to see an example, please contact any of the investigators:

Sarah Spence MD PhD spences@mail.nih.gov

Audrey Thurm PhD athurm@mail.nih.gov

Fred Volkmar MD fred.volkmar@yale.edu 